Wolfgang Hofkirchner, Manfred Tscheligi, Robert Bichler, Wolfgang Reitberger:

\title{
Ambient Persuasion for the Good Society
}

\begin{abstract}
:
In this paper we argue for a pro-active, technology-driven as well as social problem-driven technology assessment (TA) of Ambient Persuasion technologies. Our starting point for assessing ICTs regarding ethical aspects is the vision of a Good Society (Bradley 2006), which is a Global Sustainable Information Society (GSIS). Such a society is on the way to sustainability, strongly supported by Information and Communication Technologies. Using ICTs for persuasion at the same time imply opportunities and risks. We identify two contrary persuasive strategies; the first one is mainly based on negotiated persuasion, while the second approach is a more behaviouristic one. To tap the full potential of both approaches we propose a dialectic understanding for Ambient Persuasion by presenting promising, already existing examples.
\end{abstract}

\section{Agenda}

The Ethos of the Great Bifurcation . .43

Persuasion 43

Persuasion strategies with the help of computers

Conclusion.....

\section{Authors:}

Prof. Dr. Wolfgang Hofkirchner

- ICT\&S Center - Advanced Studies and Research inInformation and Communication Technologies \& Society, University of Salzburg, Austria

- $\mathbb{2}$ + 436628044 4821, $\square$ wolfgang.hofkirchner@sbg.ac.at, 品 http://www.icts.uni-salzburg.at/hofkirchner

Prof. Dr. Manfred Tscheligi:

- ICT\&S Center - Advanced Studies and Research inInformation and Communication Technologies \& Society, University of Salzburg, Austria

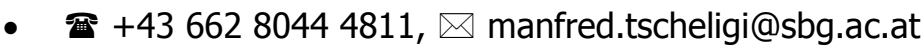

口 $\mathrm{http}: / /$ www.icts.uni-salzburg.at/tscheligi

Mag. Robert Bichler:

- ICT\&S Center - Advanced Studies and Research in Information and Communication Technologies \& Society, University of Salzburg, Austria

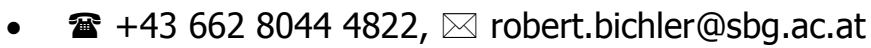

品 http://www.icts.uni-salzburg.at/bichler

DI (FH) Wolfgang Reitberger, M.Sc.:

- ICT\&S Center - Advanced Studies and Research in Information and Communication Technologies \& Society, University of Salzburg, Austria

- 偲 +43662 8044 4812, $ه$ wolfgang.reitberger@sbg.ac.at

品 http://www.icts.uni-salzburg.at/reitberger 
In the following paper we focus on a part of ubiquitous computing, that is to say, the intersection of ubiquitous computing and persuasive technology. We will argue that in spite of the danger of anthropomorphising artifacts, which would yield inhumane consequences, there is a well-definable area of Ambient Persuasion applications that are useful and socially acceptable.

\section{The Ethos of the Great Bifurcation}

The paper presented here aims at contributing to a pro-active, technology-driven as well as problemdriven (VDI 2000) technology assessment (TA) of Ambient Persuasion technologies. This assessment is both technology- and problem-driven, since it focuses on both a technology and societal or social problems to be solved by means of that technology. It is pro-active, since the technology it deals with is just emerging and solutions to the problems are yet to be found. The course of research and development might still be influenced by that kind of TA.

Not only decision makers in business, government and civil society in general are addressed. But also engineers, in particular, are expected "to acquire and strengthen their ability to play an active part in such technology assessment" and "to analyse and weigh controversial views through discussions that cross borders of disciplines and cultures" (VDI 2002, 6 ), since they are said to be "responsible for their professional actions and the resulting outcomes" (VDI 2002, 4).

Technology is not value-free. Technological action that is, design as well as usage of technologies, irrespective of the level on which design and usage may occur (the micro-level of the individual, the meso-level of groups, organisations, institutions, and the macro-level of society at all) - is constantly forced to select ends and means and the selection needs criteria, which are related to values.

Value systems build hierarchies and, according to societal conditions, values can be in conflict with each other. E.g., the guidelines of The Association of Engineers in Germany VDI 3780 concerning TA name eight basic value clusters (VDI 2000).Starting point for assessing ICTs regarding ethical aspects is the vision of a Good Society (Bradley 2006) which is a Global Sustainable Information Society (GSIS). By that we define a society that, on a planetary scale, is set on the path of sustainable development by the help of ICTs. A GSIS fulfils the requirements for a breakthrough at a point in human history when the development of societies is confronted with a possible breakdown - a situation we termed the Great Bifurcation elsewhere (Hofkirchner/Maier-Rabler 2004).

A GSIS fulfils the requirements for social acceptance in respect to social, environmental and technological compatibility. That is, we suggest that the overall value be sustainability that denotes a society's ability to perpetuate its own development. We, furthermore, suggest that sustainability be broken down into (1) social compatibility which is inclusiveness and fairness - to be broken down, in turn, into cultural equality, political freedom and economic solidarity - (2) environmental compatibilty and (3) technological compatibility - to be broken down into usefulness, usability, effectivity, reliability, security and other values. Thus there is a never-ending need to make more specific values comply with more universal values.

Designing ICTs - in technical respect as well as concerning the social context - is normative and ought to be guided by the vision of the GSIS.

\section{Persuasion}

Weiser (1991) has shaped the vision of Ubiquitous or Calm Computing (UbiComp), where computers are not bound to a fixed location but are unobtrusively integrated into the environment. The computer loses its predefined place as desktop computer and can be found in new contexts and application methods. The grey box on the desktop is replaced by a magnitude of connected embedded devices. Another important feature of UbiComp is natural interaction, i.e. enabling the use of gestures, speech, gaze and movement to communicate with the system and with other users.

Fogg defines persuasive technology as "any interactive computing system designed to change people's attitudes or behaviors" $(2003,1)$. Ubiquitous interfaces, which comprise a particular class of interactive systems, have the capability to unobtrusively surround the user at any given moment and place. This enables a persuasive intervention just at the right time (IJsselstein et al. 2006). This opportune moment is also referred to as kairos (Fogg 2003). Fogg discusses several strategies for persuasive technologies, of which social acceptance, connectivity or facilitation is the most powerful persuasion strategy (Fogg 2006). Other persuasive strategies are persistence and simplicity. Persistence means 
that the system confronts the user with the persuasive message at several occasions whenever an opportune moment arises. Simplicity means that the interactive system makes it easy for the user to understand the persuasive cue and to perform the desired action.

As with the terms "interaction" and "communication", the usage of the term "persuasion" in relation to computers is best be taken metaphorical. For each of them supposes social actors, and the computer seems not to be one. It can be argued that it is a category mistake to ascribe socia(bi)lity or (social) agency to computers as actor-networktheory approaches insinuate and an anthropomorphic fallacy (Atkinson 2006).

Recognising the metaphorical meaning is consequential for the evaluation of ethical aspects of "persuasive technology". Persuasion has been dealt with by rhetorics, communication studies, psychology and psychotherapy before or independently of the advent of computers (Borchers 2002, Fotheringham 1966, Jowett/O'Donell 1999, Jabusch/Littlejohn 1990). "Persuasion", etymologically, goes back to the Latin verb "persuadere". Though the root syllable "suadere" had the meaning of "to advise", "suasio" the meaning of "recommendation" and "suasor" the meaning of "counselor", there is a latent ambiguity with the term "persuadere" which is prevalent up to now. This ambiguity is obscured in the English notion of persuasion but shows up clearly in the German distinction between "Überzeugung" and "Überredung". While the first term has a positive connotation, the second one has a negative one. The first one is related to an interaction and communication style of social actors that appeals to rationality by the provision of (logical) arguments, but does, at the same time, not violate the autonomy and freedom of choice of the "persuadees". The second, however, might be characterised by the application of non-, a- or irrational techniques by the "persuaders" which might be deemed ethically questionable (comp. Petty et al. 1996) and not in accordance with the humane vision of a GSIS.

We apply a three-level model of communication (Hofkirchner 2002), taking advantage of semiotic concepts. On the lowest level, we identify the syntactical aspect of communication, which is about the code that has to be shared by both the communicator and the communicant. The second level is the semantic level. Here communicator and communicant refer to something which is the content they discuss. It is on the uppermost level where persua- sion enters the scene. The pragmatics of communication is about the social relationship of the participants in the communication process, it is about the intention and motivation which is the reason why communicator and communicant choose a certain content to talk about, it is about the values underlying the communication process. Having said this, the intention of the persuader is to make the persuadee share the same values. One option - the one that seems ethically sound - is, on the semantic level, to look for agreements as many as possible on facts that, on the pragmatic level, are compatible with, and do not contradict, the values the persuader wants the persuadee to share. It is important to remark here that values cannot be derived from facts and that hence the persuadee cannot logically be enforced to adopt values. There is still a leap in quality and it is up to the decision and free choice of the persuadee to adopt certain values or not. The other option - which is contested from the point of view of humanism - is to put weight on the pragmatic level only without resorting to arguments on the semantic level in their own right.

\section{Persuasion strategies with the help of computers}

When transposed to the computer, the problem arises which of the two styles and techniques shall and can be transferred. It is clear that it is the first style that ought to be selected. However, it is doubtful whether it is applicable, since the computer cannot argue in the same way a social actor is able to do and the persuadee cannot argue with the computer in the same way he would do with another social actor. Therefore the application of computers as means of persuasion is limited. What computers can do, is, by providing cues, to support the inviolable right of humans to decide on their own. They can raise the awareness of certain problems, but it seems inappropriate to design them for doing more than that.

The temptation to resort to models that remind of behaviouristic-style approaches when ICTs enter the stage is big. The bulk of psychological investigations, however, seems to already prioritize the second way of persuasion (comp. Wood 2000). These two different persuasive strategies are similar to the ones laid out in the Elaboration Likelihood Model (ELM) (Petty et al. 2005). The central route to persuasion involves the presentation of arguments, which are central to the issue at hand and require careful thinking and deliberation on the side of the 
recipient or persuadee. On the contrary, the peripheral route requires much less cognitive processing and relies more on aspects like the attractiveness of the source, the message length or the presence of positive or negative stimuli in the context in which the message was presented.

Generally speaking, using the central route to persuasion can lead to long-term attitude and behavioral change. Also, the attitudes formed this way can be easily called to mind, which is key for rational decision-making. The peripheral route leads to a significantly different outcome: The achieved attitude change is much less sustainable, and the attitudes are less accessible to the conscious mind.

Based on our ethical concerns and also out of pragmatic considerations it would seem that the central route is the far superior approach. What could be better than persuading someone with rational arguments and achieving long lasting results at the same time? The problem is that in order to utilize the central route several preconditions have to be met. The persuadee has to have ample time for considering and thinking about the arguments presented, he has to be sufficiently motivated to do so and he should not be distracted while doing so. Since this is not always the case when a persuasive argument is brought forward to a user, we propose a dialectic approach for Ambient Persuasion.

The first persuasive argument regarding a particular issue is presented via the central route of persuasion when the user is undisturbed and has ample time for consideration. When the user agrees that he wants to change his behavior based on the arguments presented, peripheral cues are presented to him during his everyday live in the right situation in order to guide his behavior towards the desired goal.

An example for an application built on this new paradigm for Ambient Persuasion is the perFrames approach. perFrames aims to persuade users towards better sitting habits while working at a computer. The process in which the application is used is twofold. First, the user is presented arguments about the danger of bad posture and about proper sitting. When he agrees an ambient display is placed on his desk in order to provide cues about the sitting posture in order to adjust the users behavior. The user has decided based on the rational arguments presented to him. The peripheral route is only used after the conscious decision of the user in order to reinforce the desired behavior and to lead to a more sustainable behavior change.
Persuasive Interfaces that aim to improve health and well being have the advantage that people are often already motivated to lead healthier lives. They just need some support in order to make the first step towards a behavioral change or to follow through with a healthier lifestyle for an extended period of time. This is where persuasive interfaces can be utilized successfully. One category of these interfaces aims to make users exercise more. Often, they use a feedback mechanism to show the user the effect of her behavior. Examples include the Polar fitness watches or the Nike + iPod Sport Kit.

Another category of these interfaces aims to help the user to quit smoking. Important elements for the success of these interfaces are the intervention at the right time in the withdrawal process and also the combination with other medical and therapeutical modalities. Whereas current interfaces in this area usually focus only on specific parts of human health and wellbeing, future ubiquitous persuasive interfaces could be based on gathering a wide range of user data in UbiComp environments. Based on this data, the system can find the potentially most successfully approaches to improve the health of a specific user and tailor a persuasive strategy to help the user reach his individual health goals.

To give another example, UbiComp interfaces have employed persuasion successfully in order to change people's behaviors regarding environmental sustainability. Many of these interfaces aim to alter user's behavior by making them aware of the effect their actions during their everyday life have on the environment. They include a power cord which visualizes the electricity that flows through it (Gustafsson et al. 2005), persuasive appliances with integrated energy feedback (Mccalley et al. 2006) and an application showing users the impact their mobility behavior has on pollution (Obermair et al. 2006, Tscheligi et al. 2006).

Persuasive Interfaces for the environment face the problem that they do not address an issue about which most people are motivated intrinsically. Thus, they can be improved by offering the user an individual benefit on top of saving the planet. In the case of the interface for sustainable mobility, users also get timetable information and the opportunity to buy a bus ticket from their mobile phone. Another strategy to motivate users is to introduce an element of social connectivity. For example, this can be allowing the users to compare their efforts to conserve energy with their peers as a competitive and game-like feature.A future interface in this area could show the users their entire $\mathrm{CO} 2$ footprint, i.e. 
their contribution to global warming, with ambient technology. This footprint is generated in real time based on the users' everyday actions. Additionally, the system could learn from the users behavior and offer alternatives that demand less $\mathrm{CO} 2$. Through connecting the users of this application with some of their peers (friends, family members), an element of social facilitation can be introduced. This could further increase the persuasive potential of this ubiquitous persuasive interface.

\section{Conclusion}

This paper has shown that Ambient Persuasion technologies, on the one hand, inhere the risk of subdueing the individual to heteronomy exercised by technology or - mediated via technology - by other social subjects, if the persuasion strategy chosen is oriented towards depriving the individual of its autonomy. On the other hand, they inhere the potential of helping alleviate social (e.g., health and well-being) and societal (e.g., environment) problems. In order to realize this potential, underlying values of different persuasion strategies have to be made explicit and, from the engineer to the manager to the stakeholder to the politician, decisions have to be made that are in accordance to the GSIS vision of a sustainable future for humanity.

\section{References}

Atkinson, B.M.C. Captology: A Critical Review. Proc. PERSUASIVE 2006, Springer (2006), 171-182.

Borchers, Timothy A. (2002): Persuasion in the Media Age. McGraw-Hill, Boston.

Bradley, G. Social and Community Informatics Humans on the Net. Routledge 2006.

Fogg, B.J. Persuasive technology: using computers to change what we think and do. Morgan Kaufman, San Francisco, CA, 2003.

Fogg, B.J. The Six Most Powerful Persuasion Strategies. Proc. PERSUASIVE 2006, Springer (2006), 6.

Fotheringham, Wallace C. (1966): Perspectives on Persuasion. Allyn \& Bacon, Boston.

Gustafsson, A. and M. Gyllenswärd. "The poweraware cord: energy awareness through ambient information display." In CHI '05 Extended Abstracts on Human Factors in Computing Systems (Portland, OR April 2005). CHI '05. New York: ACM Press, 1423-1426.

Hofkirchner 2002 Projekt Eine Welt: Kognition Kommunikation - Kooperation. Versuch über die
Selbstorganisation der Informationsgesellschaft. In: Kornwachs, K. (Hg.), Technikphilosophie, Bd. 9, LitVerlag, Münster.

Hofkirchner, W., Maier-Rabler, U. The Ethos of the Great Bifurcation. In: IRIE, Vol. 2, Nov. 2004.

IJsselsteijn, W., Kort, Y.d., Midden, C.J.H., Eggen, B., and Hoven, E.v.d. Persuasive Technology for Human Well-Being: Setting the Scene. Proc. PERSUASIVE 2006, Springer (2006), 1-5.

Jabusch, David M./Littlejohn, Stephen W. (1990): Elements of Speech Communication. Collegiate Press, San Diego.

Jowett, Garth S./ O'Donnell, Victoria (1999): Propaganda and Persuasion. Sage Publications, Thousand Oaks, London, New Delhi.

Mccalley, L.T., F.G. Kaiser, C.J.H. Midden, M. Keser, and M. Teunissen. "Persuasive appliances: Goal priming and behavioral response to productintegrated energy feedback. "In Persuasive 2006 Proceedings Berlin, Germany: Springer.

Obermair, C., Ploderer, B., Reitberger, W., and Tscheligi, M. Cues in the environment: a design principle for ambient intelligence. Ext. Abstracts CHI 2006, ACM Press (2006), 1157-1162.

Petty, R., Cacioppo, J. (1996): Attitudes and persuasion: Classic and contemporary approaches. Westview Press, Boulder, CO.

Petty, R. E., Cacioppo, J. T., Strathman, A. J., Priester, J. (2005). To think or not to think: EXploring two routes to persuasion. In Brock, $T_{\text {., }}$ Green, M. (Ed.), Persuasion: Psychological Insights and Perspectives Thousand Oaks, California: Sage. 81-116.

Tscheligi, M., Reitberger, W., Obermair, C., and Ploderer, B. perCues: Trails of Persuasion for Ambient Intelligence. Proc. PERSUASIVE 2006, Springer (2006), 203-206

VDI (Verein Deutscher Ingenieure). Technology Assessment: Concepts and Foundations. VDI Richtlinien VDI 3780. Beuth Verlag, Berlin (2000).

VDI (Verein Deutscher Ingenieure). Fundamentals of Engineering Ethics. VDI, Düsseldorf (2002).

Weiser, M. The Computer for the Twenty-First Century, Scientific American (1991), 265 (3), 94-104.

Wood, W. Attitude Change: Persuasion and Social Influence. Annu. Rev. Psychol. (2000), 51, 539570. 